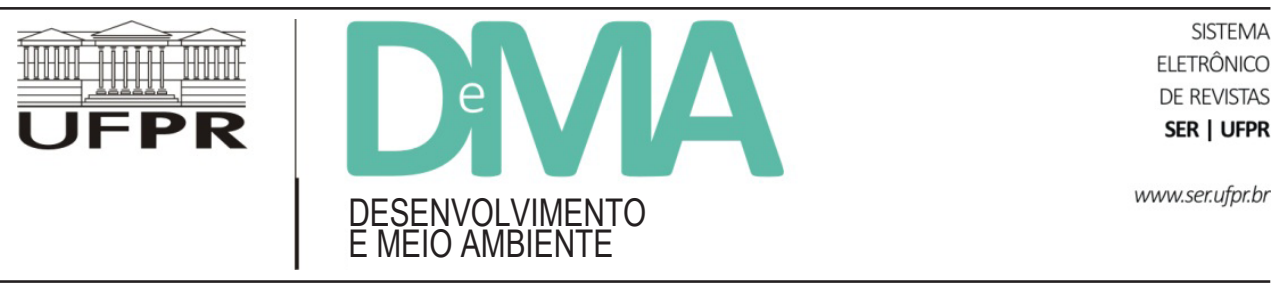

\title{
Regulação de OGMs no Brasil: aproximações com o modelo da União Europeia ou dos EUA?
}

\section{GMO Regulation in Brazil: Approximations to the EU or the USA Model?}

\author{
Denise Gallo PIZELLA ${ }^{1 *}$, Marcelo Pereira de SOUZA ${ }^{2}$ \\ ${ }^{1}$ Departamento de Biologia e Zootecnia, Universidade Estadual Paulista "Júlio de Mesquita Filho" (UNESP), Ilha Solteira, SP, Brasil. \\ ${ }^{2}$ Faculdade de Filosofia, Ciências e Letra, Universidade de São Paulo (USP), Ribeirão Preto, SP, Brasil. \\ *E-mail de contato: denisepizella@gmail.com
}

Artigo recebido em 11 de abril de 2016, versão final aceita em 6 de dezembro de 2016.

RESUMO: Há dois principais modelos regulatórios sobre OGMs que influenciam diversas nações na elaboração de seus procedimentos de gestão, sendo um mais flexível, baseado na Equivalência Substancial das variedades transgênicas com as convencionais, com os Estados Unidos da América como expoente, e outro, mais rígido, baseado em critérios estabelecidos pela União Europeia. Tendo em vista tais modelos, o objetivo deste artigo é analisar qual dos dois é utilizado como referência pelo sistema regulatório brasileiro. Para tanto, foi realizada uma revisão dos sistemas regulatórios estadunidense e europeu e analisado o parecer final de uma variedade de algodão geneticamente modificada liberada no Brasil. Constatou-se que, não obstante os questionamentos levantados por alguns de seus membros e na audiência pública realizada para a variedade de algodoeiro, a CTNBio aprovou a utilização do OGM sem solicitar maiores esclarecimentos. Deste modo, por não adotar práticas precaucionistas de gestão, o sistema regulatório de OGMs no Brasil assemelha-se ao modelo estadunidense.

Palavras-chave: transgênicos; princípio da precaução; critério de equivalência substancial.

ABSTRACT: There are two main regulatory GMO models influencing various nations in their management procedures: a more flexible one, which is based on the Substantial Equivalence criterion and has in the United States of America its exponent, and another, more precautionary, based on the European Union. Given the existence of the two above-mentioned regulatory models, the purpose of this article is to analyze which of them is used as a reference by the Brazilian regulatory system. Therefore, a review of the U.S. and European regulatory systems was performed and the Final Opinion Report of genetically modified cotton variety released in Brazil was analyzed. It was found that, although many questions were raised by some of its members and in the public hearing of transgenic cotton, CTNBio approved the use of the GMO without requesting further clarification. Thus, by not adopting precautionary management practices, the regulatory GMO system in Brazil resembles the U.S. model.

Keywords: transgenic; precautionary principle; substantial equivalence criterion. 


\section{Introdução}

Na década de 1970, o termo "biotecnologia" popularizou-se em função dos avanços em biologia celular e molecular, originando a engenharia genética (Carrer et al., 2010). Segundo a Organização das Nações Unidas, "Biotecnologia significa, qualquer aplicação tecnológica que utilize sistemas biológicos, organismos vivos, ou seus derivados, para fabricar ou modificar produtos ou processos para utilização específica." (ONU, 1992, art. 2º).

Segundo Pessôa (2007), a utilização das técnicas de biotecnologia moderna, ou seja, que faz uso de métodos de engenharia genética e de rDNA no melhoramento de plantas, caracteriza-se pela obtenção das características desejadas em um intervalo temporal menor do que com o uso dos métodos convencionais, não havendo a necessidade de compatibilidade evolutiva entre as espécies envolvidas, tornando possível a inserção do gene de uma espécie em outra.

Os principais transgenes aplicados na agricultura são aqueles que apresentam alguma utilidade aos produtores rurais, que procuram tais cultivares pelas promessas da bioindústria quanto à redução dos custos de produção, devido à diminuição do uso de agroquímicos. Consequentemente, as maiores variedades desenvolvidas são OGMs (Organismos Geneticamente Modificados) resistentes a herbicidas e que produzam substâncias inseticidas. Estes fazem parte da primeira geração de transgênicos (Nodari \& Guerra, 2001).

Os OGMs tolerantes a herbicidas caracterizam-se por apresentar genes de resistência a herbicidas, tais como o glifosato, o glufosinato de amônio e o 2,4-D, sendo as plantas modificadas mais comuns a soja, a canola, o milho e o algodão. As empresas desenvolvedoras destas culturas geneticamente modificadas (GMs) vendem aos produtores rurais o pacote tecnológico contendo a planta e o herbicida que age sobre as plantas invasoras (Robin, 2008). Já os OGMs tolerantes a insetos apresentam transgenes produtores de agrotóxicos, tendo em vista a eliminação de pragas agrícolas. A maior parte das variedades produzidas possui o gene rCry, que produz uma proteína tóxica cujas espécies-alvo são lepidópteros, coleópteros e dípteros, mas que atingem também nematoides, sarcomastigóforos e platelmintos. As culturas transgênicas deste tipo mais comuns são o algodão, o milho e a soja (Costa \& Queiróz, 2014).

Não existe um consenso no meio científico e na sociedade em geral acerca dos benefícios e dos riscos associados aos transgênicos, sendo o tema multifacetado, abrangendo questões de cunhos ambiental, social e econômico diversificadas, em um alcance mundial. Tal polêmica resulta de uma séria controvérsia científica e sociopolítica. A natureza incerta dos potenciais impactos dos OGMs, cujos riscos são imprevisíveis, já que a existência de riscos se dá diante de perigos que sejam mais ou menos perceptíveis, contribui para as discórdias acerca de sua liberação no meio ambiente ou consumo humano (Silveira \& Buainain, 2007; Levidow \& Boschert, 2008; Gonçalves, 2011; Costa \& Queiroz, 2014; Delgado, 2015).

Dadas as incertezas sobre os potenciais riscos resultantes da utilização de OGMs, mecanismos que os regulem foram elaborados por organizações multilaterais, os quais têm servido de guias para a criação de sistemas regulatórios no âmbito das nações, de acordo com suas particularidades sociais e políticas. O principal marco regulatório referente ao uso adequado de OGMs, tanto em termos de utilização interna quanto de movimentos transfronteiriços, é o Protocolo de Cartagena, que tem como premissa o princípio da precaução, que surge logo em seu preâmbulo: 
A ausência de certeza científica devida à insuficiência das informações e dos conhecimentos científicos relevantes sobre a dimensão dos efeitos adversos potenciais de um organismo vivo modificado na conservação e no uso sustentável da diversidade biológica da parte importadora, levando também em conta os riscos para a saúde humana, não impedirá esta parte, a fim de evitar ou minimizar estes efeitos adversos potenciais, de tomar uma decisão, conforme o caso, sobre a importação do organismo vivo modificado em questão [...] (Brasil, 2006).

No entanto, apesar da ratificação do Protocolo de Cartagena por uma grande gama de nações, diversas vêm adotando uma abordagem não precaucionista em relação aos OGMs, valendo-se, para isto, do critério da Equivalência Substancial como premissa para a necessidade ou não de se avaliar os potenciais riscos trazidos por estes organismos. Tal conceito se baseia na ideia de que os alimentos/ cultivares produzidos de forma convencional (ou seja, por hibridação) podem servir como elementos de comparação para os cultivares transgênicos, desde que tais cultivares tradicionais apresentem uma utilização historicamente segura do ponto de vista da saúde ambiental, animal e humana. A comparação considera os aspectos morfológicos, agronômicos e de composição genética do OGM frente a sua contraparte convencional, de modo a estabelecer seu grau de equivalência (Kuiper et al., 2002). Deste modo, a transgenia em si não é considerada um método que por si só pode conduzir ao desenvolvimento de um organismo diferenciado dos demais, não sendo necessária a adoção do princípio da precaução na utilização do OGM.

O Brasil iniciou legalmente o plantio e a comercialização de OGMs em 2005 e tem na Lei de Biossegurança os requisitos indispensáveis para a utilização destes organismos em território nacional, seja para pesquisa, plantio, comercialização ou descarte. Além desta lei, o país é regido pelo Protocolo de Cartagena, tendo-o ratificado em 2006, o qual, como visto, ancora-se no princípio da precaução para a manipulação destes organismos.

Em termos mundiais, há dois modelos regulatórios sobre OGMs, um mais flexível, que se baseia no critério da Equivalência Substancial e que tem nos Estados Unidos da América seu expoente, e outro, mais rígido e precaucionista baseado em critérios estabelecidos pela União Europeia. De modo geral, por serem modelos consolidados em termos de premissas e procedimentos utilizados na análise dos riscos dos OGMs, são frequentemente utilizados pelas demais nações do globo, que se aproximam de um ou outro principalmente em decorrência de relações comerciais.

Neste sentido, o objetivo deste artigo é analisar qual dos dois modelos de gestão de OGMs - estadunidense ou europeu - é utilizado como referência pelo sistema regulatório brasileiro, tendo por critério a adoção de uma abordagem precaucionista na gestão de OGMs ou que tenha como base a Equivalência Substancial do OGM à sua contraparte convencional. Parte-se do princípio de que ambas as abordagens fundamentam-se em pressupostos distintos em termos de procedimentos de avaliação dos potenciais impactos sociais e ambientais e de biossegurança, os quais condicionam as tomadas de decisão sobre a liberação ou não destes organismos e sua gestão pós-comercial.

\section{Procedimentos metodológicos}

Segundo Gil (2008), em termos de seus objetivos, este artigo, quanto aos seus objetivos, trata-se de uma pesquisa exploratória, envolvendo análise bibliográfica e estudo de caso e, quanto aos procedimentos, é considerado uma pesquisa documental e bibliográfica. 
$\mathrm{O}$ artigo foi estruturado do seguinte modo: inicialmente, foi realizada uma análise documental das legislações que norteiam a gestão de OGMs nos Estados Unidos da América e na União Europeia, com destaque para a aplicação do Princípio da Precaução e do critério da Equivalência Substancial, com o intuito de identificar as similaridades e as diferenças entre ambos com o sistema regulatório brasileiro. Neste sentido, foram analisadas as Diretivas 2001/18/CE e 2015/412 do Parlamento Europeu e do Conselho da União Europeia e foi feita a análise das normatizações das seguintes instituições estadunidenses: Administração de Alimentos e Drogas (Food and Drug Administration - FDA); Departamento de Agricultura (United States Department of Agriculture - USDA); Agência de Proteção ao Meio Ambiente (Environmental Protection Agency - EPA); Institutos Nacionais de Saúde (National Institutes of Health - NIHs), sendo realizada, ainda, pesquisa bibliográfica na literatura especializada.

Em um segundo momento, para uma identificação objetiva da abordagem utilizada no país na gestão de OGMs, onde se constatará a predominância do Princípio da Precaução ou do critério da Equivalência Substancial, foi analisado o processo decisório envolvendo o Algodão Roundup Ready (RR), desenvolvido pela empresa Monsanto e liberado para plantio e comercialização no Brasil no ano de 2008. Neste sentido, foram analisados os aspectos abordados no Parecer Final elaborado pela Comissão Técnica Nacional de Biossegurança (CTNBio), assim como os questionamentos levantados pelos membros de suas Câmaras Setoriais e pela audiência pública realizada antes da tomada de decisão.

Além da análise do processo de liberação do algodão RR da Monsanto, buscou-se identificar a predominância do uso dos princípios e critérios em questão para todos os OGMs de uso agrícola liberados no país até o momento. Para tanto, foram consultados os pareceres técnicos destas variedades elaborados pela CTNBio, de forma a identificar se foram consideradas equivalentes substancialmente às cultivares convencionais ou não, para então inferir com qual modelo regulatório o Brasil guarda maior similaridade, se o estadunidense ou o europeu.

\section{Resultados e discussões}

\subsection{Sistema regulatório de OGMs nos Estados Unidos da América}

Os EUA são os principais produtores mundiais de variedades geneticamente modificadas e concentram as principais empresas de biotecnologia do mundo (National Agricultural Statistics Service, 2009). A regulação dos cultivos geneticamente modificados no país se baseia no critério de Equivalência Substancial entre o OGM e a sua contraparte convencional. Caso sejam considerados equivalentes, os critérios para o plantio e a comercialização do OGM passam a ser idênticos àqueles de sua contraparte convencional (Kingsbury, 1988; Kormos \& Hughes, 2000; The Center for Food Safety, 2007). Este tipo de regulamentação é convencionalmente denominado de "baseado no produto" (Vàzques-Salat et al., 2012; Vigani \& Olper, 2013).

As primeiras agências governamentais a elaborar diretrizes voluntárias para a regulação da transgenia nos Estados Unidos da América foram os National Institutes of Health (NIHs), a partir das deliberações provenientes da Conferência Internacional de Asilomar, realizada em 1975, com o objetivo de delinear medidas para a prevenção de acidentes laboratoriais envolvendo o escape de organismos 
geneticamente modificados pela técnica do DNA recombinante. Até 1978, a liberação de OGMs no meio ambiente era proibida pelos NIHs, os quais passaram, a partir deste momento, a afrouxar as normas para sua permissão (Kingsbury, 1988).

Em 1986, uma instrução normativa criou o Coordinated Framework for Regulation of Biotechnology, composto pela Agência de Proteção Ambiental (EPA), pelo Departamento de Agricultura dos Estados Unidos (USDA), pela Administração de Alimentos e Drogas (FDA) e pelo órgão responsável pela Saúde e Segurança no Trabalho (OSHA), instituições responsáveis pela regulação de OGMs no país (The Center for Food Safety, 2007).

As agências mencionadas possuem papéis diversos concernentes à regulação de OGMs. O Departamento de Agricultura busca assegurar que o organismo não se comporte como uma planta invasora quando utilizado na agricultura. AAgência de Proteção Ambiental responsabiliza-se em fixar limites toleráveis dos pesticidas para a garantia da saúde ambiental e animal, sendo responsável pelos OGMs produtores de inseticidas, enquanto que a FDA busca assegurar a proteção da saúde humana e dos demais animais que consumam OGMs (Kingsbury, 1988; Kormos \& Hughes, 2000; The Center For Food Safety, 2007; Twardowski \& Malyska, 2015).

É importante salientar que a regulação de OGMs nos EUA baseia-se nos produtos derivados da biotecnologia e não no processo que conduz ao desenvolvimento de um transgênico. Isto significa que não se considera a técnica da transgenia em si como passível de criar um novo organismo que estaria sujeito a uma avaliação especial, dadas as incertezas relacionadas ao seu uso biosseguro (Lynch \& Vogel, 2001; Twardowski \& Malyska, 2015).

A partir de 1987, os requisitos para a aprovação de ensaios de campo com OGMs tornaram-se menos complexos, passando para um processo de notificação, que se estabeleceu a partir de 1993, sendo mais simplificado a partir de 1997 (Jesus \& Plonski, 2006).

A partir deste momento, milhares de OGMs foram liberados para plantio e comercialização sem licenciamento, perfazendo um total de $97 \%$ das solicitações para liberações comerciais (Kormos \& Hughes, 2000). Tal modificação no marco regulatório dos EUA se deu por uma política de incentivo à biotecnologia no país (Jesus et al., 2006). Além de não adotar procedimentos rígidos de avaliação de OGMs somente pelo fato de terem sido desenvolvidos pelo método de engenharia genética (regulação baseada no produto e não no processo), o país também não possui uma normativa geral para a rotulagem de alimentos transgênicos ou que contenham traços de transgênicos, por não considerar a técnica arriscada em si (Lynch \& Vogel, 2001). No entanto, há iniciativas neste sentido, como a criação de uma norma para a rotulagem de alimentos que possuam traços de transgênicos no estado de Vermont, o primeiro estado norte-americano a adotar o procedimento (Shoemaker-Kiess \& Socha, 2015).

Além das notificações, também se possibilita ao produtor a solicitação de desregulamentação para produtos regulados, desde que comprovada sua inocuidade ao meio ambiente. Os órgãos responsáveis pela gestão podem também desregulamentar OGMs de forma unilateral, sem a solicitação por parte dos produtores, baseando-se em sua similaridade com outra variedade desregulamentada. Dentre os OGMs desregulamentados estão a abóbora e o algodão, ambos possuidores de variedades selvagens aparentadas no país (Kormos \& Hughes, 2000).

A Agência de Proteção Ambiental estadunidense regulamenta os OGMs que produzem inseticidas e que fazem uso de herbicidas (Twardowski \& Malyska, 2015). Como requisito para o 
registro destes agrotóxicos, o proponente necessita apresentar evidências que comprovem sua inocuidade ao meio ambiente. Neste sentido, requer-se a realização de testes em campo, com a solicitação de uma Licença de Uso Experimental quando de sua liberação no meio ambiente sem barreiras de contenção (Kormos \& Hughes, 2000).

A concessão da licença é dada automaticamente para produtos similares substancialmente a outros já aprovados, sendo o caso da maioria dos OGMs liberados no país (Kormos \& Hughes, 2000).

Em novembro de 1994, a Agência de Proteção Ambiental publicou uma norma que dispensa a regulação de pesticidas que não ofereçam elevados riscos aos organismos não-alvo para as culturas agrícolas. Como critério inicial para a dispensa da regulação, a Agência avalia o grau de novidade do pesticida em relação à planta receptora e ao meio ambiente, como são os casos de pesticidas derivados de plantas aparentadas evolutivamente. Críticos dos critérios de dispensa argumentam sobre a necessidade de se considerar a quantidade de pesticidas produzidos pela planta transformada, a qual poderia ser maior em plantas GMs devido a mudanças genéticas quantitativas (Kormos \& Hughes, 2000).

O papel da FDA é o de prevenir a comercialização de alimentos que contenham produtos prejudiciais à saúde humana, incluindo aditivos e pesticidas não aprovados, além de possuir autoridade para a remoção de alimentos que se mostrem perigosos à saúde humana durante sua comercialização, com a imposição de sanções criminais a produtores que descumprirem a legislação. A agência realiza a avaliação pré-comercial dos alimentos contendo aditivos, a menos que estes se enquadrem na cláusula "Generally Recognized as Safe" (GRAS), no caso de alimentos que não apresentem novas substâncias, sendo considerados inócuos à saúde. Apesar das controvérsias a respeito do grau de novidade dos produtos geneticamente modificados, considerados aditivos por alguns analistas, diversos alimentos GMs ou contendo OGMs são enquadrados como seguros, sob a justificativa da equivalência substancial (Kormos \& Hughes, 2000; Moore, 2002; Pelletier, 2006).

Apesar das preocupações por parte dos consumidores, a FDA não tem requerido testes pré-comerciais para alimentos derivados da engenharia genética. Com esta dispensa, a modificação no status do produto visando a sua regulação como aditivo é voluntária ou se dá quando a Agência e consumidores detectem efeitos negativos durante sua comercialização (Moore, 2000). O único OGM submetido a uma regulação pela FDA foi o Flavor Savor Tomato, da Calgene (posteriormente adquirida pela Monsanto), modificado geneticamente para apresentar um sabor diferenciado e possuir uma maior durabilidade. No entanto, problemas em seu transporte - visto que o OGM se mostrou mais suscetível a impactos nos translados - e o entendimento, por parte dos consumidores, de que o sabor prometido não era condizente com a realidade, somados a problemas financeiros da Calgene, levaram ao término de sua comercialização (Pifer, 2014).

No processo regulatório dos EUA, a participação pública limita-se às indagações e comentários durante períodos definidos na avaliação de risco. Entretanto, estudo realizado pelo National Research Council sobre as ações da FDA apresentam a falta de transparência durante a definição dos critérios de análise do risco realizadas, em função, dentre outros aspectos, das reiteradas aceitações dos pedidos de confidencialidade pelos órgãos reguladores da informação para a proteção das patentes comerciais das empresas (National Research Council, 2002). Há no país uma diferença de opiniões entre cientistas e público em geral em relação aos alimentos 
que contêm transgênicos. Enquanto a maioria do público (cerca de 57\%) declara desconfiança quanto à segurança destes alimentos, em detrimento de $37 \%$ que os consideram seguros, a maior parte dos cientistas os vê como seguros (Pew Research Center, 2015).

Evidências apontam a interferência direta da bioindústria no direcionamento das políticas de OGMs nos EUA, visando a um afrouxamento no controle das agências reguladoras para uma rápida e eficaz comercialização interna e para o aumento da competitividade e controle dos mercados internacionais. Neste sentido, Pelletier (2006) aponta para os primórdios da constituição do Coordinated Framework durante o governo Reagan, em 1984, cujas interferências do Conselho de Competitividade, solicitado a solucionar os conflitos levantados pelas agências a respeito da abordagem regulatória dos OGMs, tiveram papel determinante sobre a mesma. Deste modo, se determinou a regulação focada no produto ao invés do processo e a redução das barreiras regulatórias, nos limites de cada agência, buscando acomodar os avanços tecnológicos em lugar de controles rígidos.

A influência da bioindústria sobre a definição das políticas a respeito dos OGMs é demonstrada por Pelaez (2004), especificamente sob o lobby da Monsanto. Documento de 13 de outubro de 1986, elaborado pela empresa e parcialmente publicado no jornal The New York Times, apresenta, como solução aos entraves políticos para a liberação de seus produtos advindos de OGMs, dentre os quais se destaca a soja resistente ao herbicida glifosato Roundup, comercializado pela empresa:

[...] o engajamento de representantes públicos nomeados para as agências reguladoras (FDA e EPA); e a busca de apoio político nas plataformas eleitorais, tanto no Partido Republicano quanto no Democrata, à Presidência da República de 1998 [...] uma participação ativa junto à comunidade, de forma a atrair o interesse público e obter o apoio de grupos de consumidores e de ambientalistas à biotecnologia, engajando-os inclusive como consultores da empresa (Eichenwald, 2001, p. 15).

A atribuição de funções sobre a regulação de OGMs por meio de agências já consolidadas e dotadas de confiabilidade pública, em detrimento da constituição de órgãos específicos para tanto, é explanada como uma estratégia do governo estadunidense para a aceitação pública dos OGMs, visando ao atendimento dos interesses comerciais da bioindústria (Guehlstorf, 2004 apud Guehlstorf \& Hallstrom, 2005). Deste modo, o regime regulatório incorporou a biotecnologia moderna, mas de forma a não submetê-la a um controle rígido, não obstante as incertezas quanto aos danos ambientais e à saúde humana dela decorrentes. Os órgãos reguladores justificam este posicionamento argumentando sobre a necessidade de se incentivar a competitividade agrícola, visando não apenas ao retorno econômico em curto prazo, mas também à redução dos riscos de longo prazo decorrentes do controle sobre a tecnologia (Guehlstorf \& Hallstrom, 2005; Vàzsques-Salat et al., 2012).

\subsection{Sistema regulatório de OGMs na União Europeia}

$\mathrm{Na}$ União Europeia, a área cultivada com OGMs era, em 2014, segundo Pollock \& Hails (2014), de aproximadamente 0,1 milhão de hectares, frente aos 170 milhões de hectares presentes em todo o mundo.

Nas duas últimas décadas, a União Europeia vem estabelecendo princípios e normas comuns para reger o processo de regulação dos OGMs em 
seus países-membros. Possuindo uma legislação ambiental ancorada no Princípio da Precaução, as diversas diretivas concernentes ao tema definem um processo de avaliação cauteloso, com critérios rígidos e menos tendenciosos aos interesses da bioindústria do que nos EUA. O objetivo é a garantia de segurança dos produtos à saúde humana e animal e ao meio ambiente, por meio de normas específicas para sua liberação no meio ambiente e comercialização (Saeglitz \& Bartsch, 2003).

O regime regulatório da UE concebe as variedades transgênicas como originais e distintas das produzidas pelos métodos convencionais, levando à necessidade de sua avaliação de forma separada, abrangendo a identificação das características que possam ocasionar efeitos adversos, à avaliação de suas consequências potenciais com a probabilidade de ocorrência e à estimativa do risco para cada característica do OGM (Saeglitz \& Bartsch, 2003). Tal tipo de regulamentação é denominada de "baseada no processo", pois é relevante o fato de o cultivar ter sido elaborado por meio da transgênese (Vàzques-Salat et al., 2012; Vigani \& Olper, 2013).

Devido às limitações dos parâmetros e espécies disponibilizados para exames laboratoriais de biossegurança e ao reconhecimento sobre a complexidade das relações intra e interespecíficas nos ecossistemas, considera-se a necessidade de monitoramento em campo caso a caso após a permissão para o plantio, com o intuito de se detectar possíveis efeitos adversos (Saeglitz \& Bartsch, 2003).

A avaliação de risco deve comprovar a ausência de efeitos adversos do OGM, a garantia de informações aos consumidores e uma qualidade nutricional adequada (Varzakas et al., 2007). A avaliação de risco ambiental deve incluir os seguintes pré-requisitos: impactos do fluxo gênico vertical fora e dentro da área de plantio e suas consequências (inclusive socioeconômicas); impactos da transferência genética horizontal sobre os micro-organismos; impactos sobre organismos não-alvo e impactos das variedades contendo genes inseticidas sobre a biodiversidade agrícola.

A respeito da normatização de alimentos derivados de OGMs, tanto para consumo humano quanto para os demais animais, a Regulação 1829/2003 estipula a necessidade de avaliações de segurança pelo proponente, além de uma avaliação independente pela European Food Safety (EFSA). Por esta regulação, o proponente deve garantir que o produto esteja de acordo com os requisitos de rastreabilidade e rotulagem (caso contenha mais de $0,5 \%$ de produto geneticamente modificado) e realizar o monitoramento pós-comercial, a fim de demonstrar o cumprimento das normas estabelecidas (Varzakas et al., 2007; Twardowski \& Malyska, 2015).

A regulamentação a respeito da liberação dos OGMs no meio ambiente e sua comercialização se faz presente na Diretiva 2001/18 EC e determina que a avaliação de risco se realize caso a caso, considerando os possíveis impactos cumulativos e em longo prazo provenientes da interação entre OGMs e outros organismos não modificados, o que torna o monitoramento pós-comercial obrigatório (Pollock \& Hails, 2014). A liberação ambiental é realizada em etapas, com o confinamento sendo progressivamente reduzido, à medida que a segurança é demonstrada nas etapas precedentes. Os procedimentos para a autorização consistem na notificação da autoridade competente do estado destinado à liberação, por meio da apresentação de uma avaliação completa dos riscos ambientais, das medidas de segurança em casos emergenciais e de informações sobre a embalagem e rotulagem do produto (European and Parlament Council, 2001).

Com o intuito de adotar uma abordagem precaucionista a avaliação de risco deve ter por princípios: a análise comparativa do OGM com sua 
contraparte convencional; ser transparente e assentada em bases científicas atualizadas; realizada caso a caso e passível de revisão. Dentre as informações necessárias, devem constar as características dos organismos doador, vetor e receptor e das espécies ou variedades relacionadas, das alterações genéticas, da liberação ou utilização prevista e sua escala, além do ambiente receptor e suas interações (European and Parlament Council, 2001).

O processo para a utilização comercial de um OGM no meio ambiente consiste em uma notificação inicial ao país-membro de destino. A autoridade competente receptora da notificação envia o resumo do dossiê elaborado pelo requerente à Comissão Europeia, a qual o transmite aos demais países-membros, que podem se pronunciar em um período de 60 dias. Caso objeções justificadas não sejam realizadas findo este prazo, a Comissão emite parecer favorável à liberação, As notificações são suscetíveis de ser alteradas quando se detectam possíveis efeitos deletérios imprevistos após a liberação e sob novas informações adquiridas a respeito do organismo em questão (European and Parlament Council, 2001).

De acordo com a Diretiva 2001/18 EC, depois de concedida a autorização, os países-membros não poderiam proibir, restringir ou impedir a liberação do OGM em seu território, salvo se houvesse justificativas que atestassem sua periculosidade, por meio de uma cláusula de salvaguarda. No entanto, houve modificações nesta normativa, por meio das Diretivas 2002/53/EC e 2002/55/EC, as quais passaram a permitir que os países-membros proibissem, sob determinadas condições, o uso de uma variedade transgênica em todo ou em parte de seu território (European and Parlament Council, 2015).

De posse destas informações, o estado-membro em questão comunica a Comissão, que encaminha a solicitação ao Comitê formado por representantes dos países-membros e a decisão se dá em votação majoritária. Não havendo objeções justificadas à proposta de liberação, a autoridade competente emite parecer favorável à mesma (European and Parlament Council, 2001).

No caso de rejeição da proposta, o Comitê submete a decisão ao Conselho Europeu, o qual pode decidir a favor da autorização por meio de votação majoritária ou pela rejeição, em decisão unânime. Passados três meses da consulta ao Conselho e não havendo qualquer manifestação de sua parte, a decisão é tomada pela Comissão Europeia. No tocante à participação pública no processo de tomada de decisões, a Diretiva a faculta aos países-membros (European and Parlament Council, 2001).

Apesar da permissão legal para a comercialização de OGMs, há poucas variedades sendo comercializadas na UE, fato atribuído aos altos custos das análises de risco e monitoramento, assim como pela oposição pública, que percebe os transgênicos como produtos não naturais e também teme que possam causar consequências deletérias à saúde humana e aos ecossistemas, apresentando desconfiança quanto à capacidade regulatória de seus governos. Desta forma, poucas solicitações para o cultivo de OGMs foram realizadas (Vàzques-Salat et al., 2012; Twardowski \& Malyska, 2015). Desde 1997, as preocupações da sociedade, principalmente por parte dos consumidores e grupos ambientalistas, têm influenciado as decisões políticas de diversos países-membros, conduzindo alguns (França, Alemanha, Hungria, Polônia, Bulgária, Itália, Luxemburgo, Áustria e Grécia) à decisão sobre a moratória da produção e comercialização de OGMs em seu território, por meio do uso da cláusula de salvaguarda presente na Diretiva 2001/18/EC (Saeglitz \& Bartsch, 2003; Twardowski \& Malyska, 2015). 


\subsection{O modelo brasileiro regulatório de OGMs no Brasil}

No Brasil, a Lei Federal no 11.105 de 2005 atribui à CTNBio - Comissão Técnica Nacional de Biossegurança - a tomada de decisão sobre estudos e liberação ambiental de OGMs, a partir de um protocolo de análise. Ela é composta por 27 membros, que atuam nas áreas de biotecnologia, biossegurança, biologia, saúde humana e animal e meio ambiente (Brasil, 2005).
Os assuntos encaminhados à CTNBio são analisados em subcomissões setoriais das áreas de saúde humana e animal, meio ambiente e vegetal, integradas por membros da CTNBio. As aprovações finais são submetidas ao plenário de todos os membros que constituem a Comissão (Brasil, 2005). Os processos de liberação comercial de OGMs submetidos à CTNBio e o respectivo Protocolo de Análise são ilustrados na Figura 1.

As etapas ilustradas na figura 1 são detalhadas na Tabela 1 a seguir.

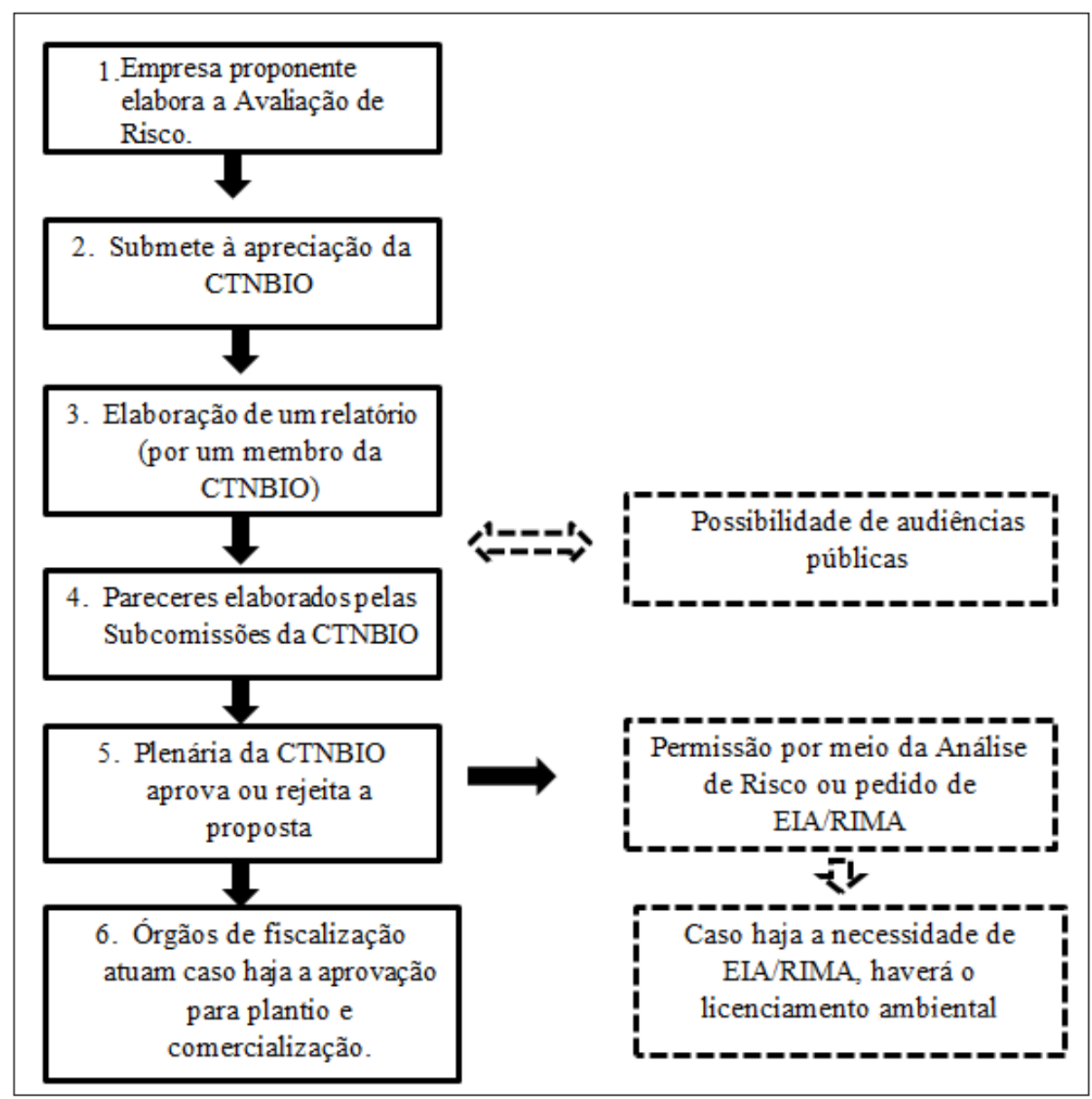

FIGURA 1 - Fluxograma do Protocolo de Análise da CTNBio para a tomada de decisões sobre a liberação de OGMs.

FONTE: Organizado pelos autores. 
TABELA 1 - Detalhamento do Protocolo de Análise da CTNBio para a tomada de decisões sobre a liberação de OGMs.

\begin{tabular}{cl}
\hline 1 & $\begin{array}{l}\text { As empresas proponentes realizam as avaliações ambientais e de biossegurança do OGM, a partir do instrumento } \\
\text { Avaliação de Risco. }\end{array}$ \\
\hline 2 & $\begin{array}{l}\text { A solicitação para a liberação comercial, com a respectiva Avaliação de Risco, é protocolada na Secretaria Executiva } \\
\text { da CTNBio e as informaçes gerais a respeito do OGM são divulgadas no Diário Oficial da União. }\end{array}$ \\
\hline 3 & $\begin{array}{l}\text { A solicitação da empresa à CTNBio é encaminhada a um ou mais membros da CTNBio para a elaboração de um } \\
\text { relatório. }\end{array}$ \\
\hline & $\begin{array}{l}\text { Este relatório é submetido às subcomissões das áreas de Saúde Humana e Animal, Vegetal e de Meio Ambiente, para } \\
\text { a elaboração de um parecer a ser submetido à plenária da CTNBio. O relatório deve ser fundamentado pela literatura } \\
\text { científica existente, pelos documentos protocolados nas audiências públicas (caso ocorridas, pois a Lei Federal no }\end{array}$ \\
& $\begin{array}{l}\text { 11.105 de } 2005 \text { prevê uma participação de diferentes setores sociais, a critério da CTNBio) e esclarecer as opiniões } \\
\text { divergentes de cada um dos membros da referida subcomissão. }\end{array}$ \\
\hline 5 & $\begin{array}{l}\text { O parecer das subcomissões é encaminhado ao plenário da CTNBio para deliberação final, que será fundamentada, } \\
\text { explicitando as medidas ambientais e de biossegurança a serem adotadas, as restriços de uso e considerações sobre } \\
\text { as particularidades das diferentes regiões do país. }\end{array}$ \\
\hline 6 & $\begin{array}{l}\text { Este parecer final subsidia as ações dos órgãos de registro e fiscalização dos OGMs no Brasil, quais sejam: } \\
\text { Ministérios da Saúde; Agricultura, Pecuária e Abastecimento; Meio Ambiente e Secretaria Especial de Aquicultura e } \\
\text { Pesca da Presidência da República. }\end{array}$ \\
\hline $\begin{array}{l}\text { O licenciamento ambiental somente é requerido quando o plenário dos membros da CTNBio considerar a atividade } \\
\text { como potencialmente causadora de impactos ambientais. }\end{array}$ \\
\hline
\end{tabular}

FONTE: Organizado pelos autores.

Cabe ressaltar que a Lei Federal $n^{\circ} 11.105$ de 2005 prevê a criação e implantação do Sistema de Informações em Biossegurança (SIB), que tem por função disponibilizar as informações sobre a biossegurança de OGMs no Brasil e as tomadas de decisão a seu respeito. Da mesma maneira, a referida lei institui o Sistema Nacional de Biossegurança, composto por órgãos do governo federal, que também tem como atribuição formular e implementar a Política Nacional de Biossegurança (PNB). Contudo, tanto a PNB e o SIB ainda não foram elaborados e implantados.

\subsubsection{Análise do procedimento de liberação do Algodão Roundup Ready (RR) evento MON 1445, da empresa Monsanto do Brasil}

O algodão RR foi modificado a partir da variedade comercial Coker 312 por meio do sistema
Agrobacterium tumefaciens. A transformação confere a resistência da linhagem ao herbicida glifosato (CTNBio, 2008b).

$\mathrm{Na}$ audiência pública realizada em 17 de agosto de 2007, seis eventos foram submetidos à discussão: o algodão Liberty Link (LL), evento LL Cotton 25 e algodão LL, ambos resistentes ao herbicida glufosinato de amônio; algodão RR, evento MON1445, tolerante ao herbicida glifosato, e algodão Bolgard (Bt), evento MON15985 tolerante aos insetos da Ordem Lepidoptera, ambos da Monsanto, além do algodão Widestrike, evento 2813006, com dupla resistência, tanto ao glifosato quanto aos insetos. Como todos os eventos analisados possuem características comuns, pertencentes ao mesmo cultivar e com transgenes que conferem características de resistência a herbicidas ou insetos, a audiência pública foi realizada para se discutir os potenciais impactos sociais, econômicos e am- 
bientais derivados destas seis variedades geneticamente modificadas em conjunto. Entretanto, serão considerados apenas os aspectos abordados para o algodão RR da Monsanto, a título de exemplo.

Quanto ao critério "Equivalência Substancial", a CTNBio considerou a variedade equivalente substancialmente ao algodão convencional, baseando-se nas análises fenotípicas e de desempenho agronômico apresentadas pela Monsanto. A única diferença seria a expressão do gene que confere resistência ao herbicida glifosato, mas que, segundo a Comissão, não seria um fator suficiente para diferenciar o algodão transgênico do convencional (CTNBio, 2008b).

Os relatórios apresentados pelos pareceristas da CTNBio apresentaram divergências neste aspecto em uma mesma subcomissão setorial. $\mathrm{Na}$ Subcomissão Vegetal e de Meio Ambiente, questionou-se a respeito das diferenças entre as técnicas de melhoramento convencional e transgenia e de como a inserção de genes não nativos poderia ocasionar efeitos imprevisíveis. Um dos pareceristas da Subcomissão de Saúde Humana e Animal também argumentou sobre a incerteza da equivalência, em razão da falta de mais estudos a serem realizados pela empresa, os quais se basearam nas proteínas isoladas expressas pelos transgenes e não no organismo como um todo (CTNBio, 2008b). Com relação aos questionamentos presentes na audiência pública, apresentaram-se argumentos diferenciados que justificavam ou questionavam a equivalência (CTNBio, 2007).

Outro aspecto considerado foi o potencial de toxicidade e alergenicidade do OGM para animais, incluindo o ser humano. A conclusão pela equivalência substancial do OGM constitui-se em pré-requisito para afirmações em torno da inocuidade destes organismos quando comparados aos convencionais. ACTNBio, em seu parecer final, concluiu a respeito da inocuidade, fato questionado por alguns pareceristas de suas duas subcomissões, que apontaram pela incerteza dos resultados, já que foram realizados em um curto espaço de tempo, além de não terem sido analisados a fisiologia, a morfologia e o peso dos órgãos dos animais estudados (CTNBio, 2008b). As opiniões na audiência pública também foram contraditórias, com argumentos que defenderam a inocuidade do OGM e outros que abarcaram sua controvérsia (CTNBio, 2007).

Quanto ao critério de potencial fluxo gênico, o parecer final da CTNBio concluiu sobre sua impossibilidade e considerou que, durante o transporte do OGM, algumas sementes poderiam se estabelecer nas estradas e portos, mas os riscos ambientais seriam mínimos se se encontrassem fora de áreas agrícolas (CTNBio, 2008b). Na audiência pública, houve controvérsias entre aqueles que apontaram para o baixo risco de fluxo gênico e introgressão nas espécies receptoras, enquanto que outros participantes abordaram uma série de questões, como a desconsideração, nas análises realizadas pela empresa, das áreas de plantio de algodão agroecológico nas zonas de exclusão definidas pelo Ministério da Agricultura, Pecuária e Abastecimento - MAPA, o que seria uma ameaça à perda da certificação destes produtos (CTNBio, 2007). O parecer final da CTNBio concluiu pelo risco mínimo de fluxo e introgressão gênica (CTNBio, 2008b).

Em relação às vantagens econômicas da liberação do algodão RR, a CTNBio argumentou pelo aumento da produtividade obtida com a redução do uso de herbicidas pela variedade. Os pareceristas das Subcomissões Vegetal e de Meio Ambiente valorizaram estes mesmos aspectos, acrescentando a inexistência de cultivos geneticamente modificados improdutivos no Brasil e até o maior desenvolvimento do cultivo quando utilizadas as doses indicadas do glifosato na época recomendada. Os 
relatores da Subcomissão de Saúde Humana e Animal também abordaram a mesma questão, salientando a necessidade de não se utilizar uma dosagem maior do herbicida, que poderia ocasionar riscos de toxicidade. No entanto, um dos pareceristas da Subcomissão Vegetal e de Meio Ambiente apresentou uma série de desvantagens com a liberação do OGM em questão, tais como um possível aumento dos custos das sementes, fato sucedido com a soja RR, também da Monsanto, cujo aumento se deu na ordem de $16,67 \%$ na safra 2008/2009, além da não comprovação de aumento nos rendimentos por parte dos agricultores que adotaram cultivos geneticamente modificados (CTNBio, 2008b).

Os participantes da audiência pública apresentaram argumentos favoráveis e desfavoráveis neste aspecto (CTNBio, 2007).

Quanto ao monitoramento pós-comercial da variedade transgênica, questionou-se, na audiência pública, a ausência de monitoramento e fiscalização de OGMs no Brasil pelos órgãos responsáveis, a impossibilidade de estes participarem nas tomadas de decisões a respeito da liberação de OGMs e a falta de articulação institucional (CTNBio, 2007).

Analisando o estudo de caso com o algodão RR da Monsanto em seu processo de liberação comercial, percebe-se que, em todos os aspectos considerados para subsidiar a tomada de decisão acerca de sua liberação ambiental presentes no Parecer Final da CTNBio, não houve quaisquer considerações acerca das incertezas científicas abordadas por pareceristas e pelos participantes da audiência pública. Deste modo, conclui-se pela não adoção do princípio da precaução, tanto na tomada de decisão quanto na gestão dos plantios desta variedade de algodão, o que levaria à necessidade de uma análise de risco mais criteriosa antes de sua liberação ambiental e em um monitoramento pós-comercial efetivo.
Analisando-se os Extratos de Pareceres da CTNBio para as demais variedades agrícolas geneticamente modificadas liberadas no Brasil, como o feijão, doze variedades de algodão, vinte de milho e cinco de soja, observa-se que todos foram considerados equivalentes substancialmente às suas contrapartes convencionais (conforme a solicitação da adoção do critério por parte das empresas proponentes), o que lhes conferiu o status de seguros do ponto de vista da saúde animal e humana e inócuos ao meio ambiente.

Em todas as situações analisadas, percebe-se que o princípio da precaução, que rege a política ambiental brasileira, consta do art. $1^{\circ}$ da Lei 11.105 e está presente no Protocolo de Cartagena, foi desconsiderado mesmo sem a apresentação de evidências que constatassem a biossegurança das variedades geneticamente modificadas. Inversamente, consta, tanto no Parecer Final do algodão RR quanto das demais variedades analisadas, a equivalência substancial destas às suas contrapartes convencionais, não obstante a ausência de critérios cientificamente embasados que a justificassem. Nesta questão, decisiva para a condução de uma análise de risco mais criteriosa, com estudos de campo a longo prazo e testes laboratoriais independentes daqueles fornecidos pela empresa proponente dos OGMs, o sistema regulatório brasileiro referente a estes organismos se assemelha ao estadunidense, o qual utiliza o critério da Equivalência Substancial para desregulamentar as atividades que envolvam OGMs em seu território.

\section{Conclusões}

Os sistemas regulatórios de OGMs adotados pelas nações se baseiam em dois modelos de gestão, bastante diferenciados entre si, que são o estaduni- 
dense e o europeu. O modelo adotado pelos EUA segue como critério a Equivalência Substancial, que se baseia na ideia de que os alimentos/cultivares produzidos de forma convencional (ou seja, por hibridação) podem servir como elementos de comparação para os cultivares transgênicos, utilizando como critérios os aspectos morfológicos, agronômicos e de composição genética do OGM frente à sua contraparte convencional. Deste modo, a transgenia não é considerada um método que conduz ao desenvolvimento de um organismo que possua uma potencialidade intrínseca de ocasionar prejuízos à saúde humana e animal, impactos ambientais e modificações nas práticas agrícolas. Em virtude disto, apesar de possuir, em tese, procedimento para a análise de risco para organismos que apresentem alguma novidade em seu processo de desenvolvimento e para substâncias aditivas, a prática estadunidense não condiciona os OGMs a este processo de avaliação, justamente por não considerá-los diferentes das variedades convencionais.

O modelo europeu, de forma contrária, estrutura sua gestão na percepção de que os OGMs se constituem em novos organismos, cujos potenciais impactos ao meio, à saúde e à agricultura (no caso de variedades agrícolas) são desconhecidos, incertos e imprevisíveis, o que leva à necessidade de se adotar uma postura precaucionista nos procedimentos de sua análise e utilização para quaisquer fins. Neste sentido, a Comissão Europeia realiza uma análise de risco caso a caso das atividades relacionadas a OGMs e estabelece medidas de monitoramento e rotulagem para a detecção e a mitigação dos impactos. A isto se soma o fato de que os produtos contendo transgênicos não apresentam aceitabilidade por parte da opinião pública, constituindo-se em um grande empecilho para a liberação destes organismos na maior parte dos países-membros da União Europeia. Enquanto isto há, nos EUA, um grande lobby das indústrias de biotecnologia nos setores governamentais responsáveis pelas desregulamentações de uso dos OGMs, fato que é levantado por alguns autores a fim de justificar a política de desregulamentação destes organismos naquele país.

O Brasil se encontra em uma posição de destaque quanto ao plantio de variedades agrícolas geneticamente modificadas, sendo o segundo maior produtor mundial de OGMs. Para regulamentar tais atividades, a Lei Nacional de Biossegurança estabeleceu os critérios, procedimentos e órgãos governamentais responsáveis pela gestão destes organismos, atribuindo à Comissão Técnica Nacional de Biossegurança a condição de órgão superior para análise e decisão final quanto à pesquisa, ao plantio, à comercialização e quaisquer outros usos envolvendo OGMs no Brasil.

Tendo o princípio da precaução como norteador da política ambiental brasileira, o qual se faz presente em diversos tratados e convenções internacionais ratificados pelo Brasil, assim como no Protocolo de Cartagena, que estabelece os princípios e os procedimentos gerais indispensáveis pelas atividades envolvendo OGMs em âmbito transfronteiriço, o Brasil o recepcionou em sua Lei de Biossegurança, fazendo-o princípio fundamental para balizar as análises de risco relacionadas a tais organismos.

O Princípio da Precaução, ao ser aplicado para atividades onde há incertezas científicas quanto aos potenciais riscos envolvendo a saúde humana e ambiental, conduziria a uma análise de risco criteriosa, pois parte da premissa de que tais organismos são diferentes de sua contraparte convencional devido à técnica da transgenia, conduzindo a um procedimento de avaliação dos potenciais impactos ao meio ambiente e à saúde humana e animal independente da empresa proponente e que, caso se constate pela 
biossegurança a viabilidade ambiental do OGM, a um monitoramento pós-liberação efetivo, em associação à rotulagem ambiental de alimentos contendo traços de OGMs.

A CTNBio analisa os processos apresentados pelas empresas proponentes utilizando os resultados das avaliações de risco por estas efetuados, além de considerar reduzidos ensaios de campo sob contenção efetuados em poucas localidades brasileiras. No exemplo de deliberação apresentado, qual seja, o algodão MON 1445, alguns pareceristas da Comissão, responsáveis por avaliar o processo, levantaram algumas questões: problemas de ordem metodológica da análise de risco efetuada pelo proponente e os ensaios de campo realizados no Brasil; o fato de as análises realizadas no país considerarem praticamente o desempenho agronômico das variedades, com insuficiente ponderação sobre os aspectos ambientais; os estudos realizados em poucas localidades, não levando em conta as particularidades ambientais, sociais e econômicas brasileiras; as incertezas quanto aos potenciais impactos de longo prazo, os quais são desconsiderados, dentre outros. No entanto, a Comissão não investigou estes aspectos cruciais para a liberação segura deste OGM no Brasil, o que pode comprometer tanto no presente quanto futuramente o meio ambiente e a manutenção dos demais sistemas de cultivo de algodão praticados no país.

Percebe-se pelas considerações da CTNBio em seu parecer final sobre o algodão resistente ao glifosato que apenas os comentários abordados pelos relatores que se demonstraram favoráveis à sua liberação obtiveram relevância, em detrimento dos questionamentos realizados pelos pareceristas que apresentaram os potenciais riscos advindos de sua liberação, mesmo que respaldados por estudos científicos apresentados em suas referências bibliográficas. Os argumentos levantados por estes refletem a discordância existente na comunidade científica internacional acerca dos princípios e das metodologias utilizados nas análises de risco de OGMs, tais como o critério da Equivalência Substancial, a estabilidade genética, a transferência horizontal dos transgenes, sua biodegrabilidade no solo, dentre outros. Quanto às demais variedades geneticamente modificadas liberadas no Brasil, também não houve, por parte da CTNBio, quaisquer questionamentos e exigências de estudos mais aprofundados para as empresas proponentes em nenhum dos casos analisados, sendo que, para todos, se concluiu pela equivalência substancial dos OGMs.

Como explicitado no Protocolo de Cartagena, a análise de risco necessita considerar as características do ambiente receptor do OGM, mas a empresa solicitante não apresentou tais estudos, como observado no algodão transgênico. Ao invés disto, os testes de campo foram efetuados em poucas localidades, por um curto intervalo de tempo e levaram em conta, sobretudo, os aspectos relacionados ao desempenho agronômico da variedade GM. Tal fato demonstra a inobservância do Princípio da Precaução por parte da CTNBio, já que a decisão tomada não se baseou em evidências científicas. Além disto, as preocupações da sociedade observadas na audiência pública, que também refletem as controvérsias científicas sobre os princípios e os métodos de análise de risco de OGMs, foram desconsideradas.

Observa-se, deste modo, tanto pelo exemplo analisado quanto para os demais OGMs de uso agrícola liberados no Brasil, um predomínio do critério da equivalência substancial sob a precaução nas análises efetuadas pela CTNBio, a qual é afirmada considerando somente os estudos efetuados pela empresa proponente, sem conduzi-los de modo independente. Tal constatação, além de não possuir base científica, parte da premissa que o OGM 
em análise é seguro, visto que não apresenta uma novidade científica, tornando desnecessária uma análise de risco mais criteriosa destas variedades.

Pelos motivos apresentados, pode-se concluir que o sistema regulatório de OGMs no Brasil assemelha-se ao modelo estadunidense, o qual apresenta uma avaliação de risco para estes organismos bastante flexível, baseando-se no critério da equivalência substancial, contrariamente à prática

\section{Referências}

Brasil. Lei no 11.105, de 24 de março de 2005. Regulamenta os incisos II, IV e V do $\S 1^{\circ}$ do art. 225 da Constituição Federal, estabelece normas de segurança e mecanismos de fiscalização de atividades que envolvam organismos geneticamente modificados - OGM - e seus derivados, cria o Conselho Nacional de Biossegurança - CNBS, reestrutura a Comissão Técnica Nacional de Biossegurança-CTNBio, dispõe sobre a Política Nacional de Biossegurança - PNB, revoga a Lei ${ }^{\circ} 8.974$, de 5 de janeiro de 1995, e a Medida Provisória $\mathrm{n}^{\circ}$ 2.191-9, de 23 de agosto de 2001, e os arts. $5^{\circ}, 6^{\circ}, 7^{\circ}, 8^{\circ}, 9^{\circ}, 10$ e 16 da Lei $n^{\circ} 10.814$, de 15 de dezembro de 2003, e dá outras providências. Brasília: DOU de $28 / 03 / 2005$.

Brasil. Decreto $n^{\circ} 5.705$, de 16 de fevereiro de 2006. Promulga o Protocolo de Cartagena sobre Biossegurança da Convenção sobre Diversidade Biológica. Brasília: DOU de 16/02/2006.

Carrer, H.; Barbosa, A. L.; Ramiro, D. A. Biotecnologia na agricultura. Estudos Avançados, 24(70), 149-164, 2010.

Costa, L. E. C.; Queiróz, E. S. M. Plantas geneticamente modificadas com toxinas de Bacillus thuringiensis: uma ferramenta para conferir resistência contra insetos-praga. Universitas: Ciências da Saúde, 12(2), 99-106, 2014.

CTNBio - Comissão Técnica Nacional de Biossegurança. Audiência Pública do Algodão Geneticamente Modificado. Brasília, 2007.

CTNBIO - Comissão Técnica Nacional de Biossegurança. Resolução Normativa $n^{\circ} 5$, de 12 de março de 2008. Dis- europeia, a qual apresenta uma análise de risco mais criteriosa dos OGMs, por basear-se no Princípio da Precaução.

\section{Agradecimentos}

Agradecemos à CAPES pela concessão de financiamento para a elaboração deste Projeto.

põe sobre normas para liberação comercial de Organismos Geneticamente Modificados e seus derivados. Brasília: DOU de 06/03/2008a.

CTNBIO - Comissão Técnica Nacional de Biossegurança. Parecer Técnico $n^{\circ}$ 1598/2008 sobre o processo 01200.004487/2004-48: solicitação de liberação comercial do Algodão Roundup Ready - Evento 1445. Brasília: Ministério da Ciência e Tecnologia, 2008 b.

Delgado, J. S. Transgênicos: um olhar filosófico. Revista Duc In Altum, Cadernos de Direito, 7(13), 233-251, 2015.

Eichenwald, K. Redesigning nature: hard lessons learned; Biotechnology food: from the lab to a debacle. NY Times, 25 de janeiro de 2001.

European and Parlament Council. Directive 2001/18/EC. On the deliberate release into the environment of genetically modified organisms. Official Journal of The European Union, L 106(1), 2001.

European and Parlament Council. Directive 2015/412 of the European Parliament and of the Council. Amending Directive 2001/18/EC as regards the possibility for the Member States to restrict or prohibit the cultivation of genetically modified organisms (GMOs) in their territory. Official Journal of The European Union, L 68(1), 2015.

Gil, A. C. Como elaborar projetos de pesquisa. 4. ed. São Paulo: Atlas, 2008.

Gonçalves, M. E. Entre incertezas e controvérsias: a regulação dos OGM na Europa. Nanotecnologias e OGMs: 
Ciência, Ética, Sociedade. Lisboa: CNECV, 2011. (Coleção Bioética, 12)

Guehlstorf, N. P.; Hallstrom, L. K. The role of culture in risk regulations: a comparative case study of genetically modified corn in the United States of America and European Union. Environmental Science and Policy, 8, 327-342, 2005.

Jesus, K. R. E.; Plonski, G. A. Biotecnologia e biossegurança: integração e oportunidades no Mercosul. Brasília: Embrapa Informação Tecnológica, 2006.

Kingsbury, D. T. Regulation of Biotechnology in the United States: one in a half years of using the 'Coordinated Famework'. TREE, 3, 4, 1988.

Kormos, C.; Hughes, L. Regulating Genetically Modified Organisms: Striking a Balance Between Progress and Safety. Washington: Conservation International, 2000.

Kuiper, H. A.; Kleter, G. A.; Noteborn, H. P.; Kok, E. J. Substantial equivalence - an appropriate paradigm for the safety assessment of genetically modified foods? Toxicology, 181-182, 427-31, 2002.

Levidow, L.; Boschert, K. Coexistence or contradiction? GM crops versus alternative agriculture in Europe. Geoforum, 39(1), 174-190, 2008.

Linchy, D.; Vogel, D. The Regulation of GMOs in Europe and United States: A case-study of contemporary European Regulatory Politics. Council on Foreign Relations, 2001.

Moore, E. Food Safety, Labelling and the Role of Science: Regulating Genetically - Engineered Food Crops in Canada and the United States. In: Annals of Workshop on the Politics of Food. Copenhagen, 2002, 1-34.

National Agricultural Statistics Service. Acreage. USDA, 2009. Disponível em: <http://www.ers.usda.gov/data/ biotechcrops/ExtentofAdoptionTable1.htm>. Acesso em: jan. 2013.

National Research Council. Environmental effects of transgenic plants: The scope and adequacy of regulation. Washington, DC: National Academy Press, 2002.

ONU. Convenção da Diversidade Biológica. 1992.

Nodari, R. O., Guerra, M. P. Avaliação de riscos ambientais de plantas transgênicas. Cadernos de Ciência e Tecnologia, 18(1), 81-116, 2001.
Pelaez, V. Biopoder e regulação da tecnologia: o caráter normativo da análise de risco dos OGMs. Ambiente e Sociedade, 7(2), 145-158, 2004.

Pelletier, D. L. FDA's regulation of genetic engeneered food: Scientific, legal and political dimensions. Food Policy, 31, 570-590, 2006.

Pessôa, L. T. G. Metodologia de Avaliação Ambiental Estratégica de Organismo Geneticamente Modificado na Agricultura. Rio de Janeiro, Tese (Doutorado em Ciências) - UFRJ, 2007.

Pew Research Center. Public and Scientists' Views on Science and Society, 29, 2015.

Pifer, R. H. Mandatory Labelling Laws: What Do Recent State Enactments Portend for the Future of GMOs? Penn State Law Review, 118(4), 789-814, 2014.

Pollock, C. J.; Hails, R. S. The case for reforming the EU regulatory system for GMOs. Trends in Biotechnology, 32(2), 2014.

Robin, M-M. O mundo segundo a Monsanto: da dioxina aos transgênicos, uma multinacional que quer o seu bem. São Paulo: Radical Livros, 2008.

Saeglitz, C.; Bartsch, D. Regulatory and associated political issues with respect to Bt transgenic maize in the European Union. Journal of Invertebrate Pathology, 83, 87-109, 2003.

Silveira, J. M.; Buainain, A. M. Aceitar riscos controlados para inovar e vencer desafios. In: Veiga, E. (Org.). Transgênicos: sementes da discórdia. São Paulo: SENAC, 2007. p. 23-73.

Schoemaker-Kiess, E.; Socha, A.L. Subdividing GMO classification for food labeling. Journal of Science Policy \& Governance, 7(1), 1-4, 2015.

The Center for Food Safety. Animal and Plant Health Inspection Service's Draft Programmatic Environmental Impact Assessment for the Introduction of Genetically Engineered Organisms. Riverdale, 2007.

Twardowski, T.; Malyska, A. Uninformed and disinformed society and the GMO Market. Trends in Biotechnology, 33(1), 2015.

Varzakas, T. H.; Chryssochoids, G.; Argyropoulos, D. Approaches in the risk assessment of genetic modified foods by the Hellenic Food Safety Authority. Food and Chemical Toxicology, 45, 530-542, 2007. 
Vàzques-Salat, N.; Salter, B.; Smets, G; Houdebine, L. M. The current state of GMO governance: Are we ready for GM animals? Biotechnology Advances, 30, 1336-1343, 2012.
Vigani, M.; Olper, A. GMO standards, endogenous policy and the market for information. Food Policy, 43, 32-43, 2013. 